\title{
Special issue to honour Niels Olhoff
}

\author{
G.I.N. Rozvany
}

This special issue is dedicated to Niels Olhoff, a leading researcher and organizer in the fields of mechanics and optimization. It contains extended versions of some papers presented at a meeting celebrating Niels' 60th birthday (2nd Max Planck Workshop, Nyborg, Denmark, October 2001).

Niels was born in Copenhagen, Denmark, during the Second World War in 1941. He studied at the Metropolitanskolen, obtaining his "Artium" in mathematics and physics in 1959 and his M.Sc. in Mechanical Engineering (1965). He obtained his Ph.D. in Solid Mechanics (1969) and Dr. Techn. in Optimal Engineering Design (1979) at the TU Denmark in Lyngby.

His major research interests are Solid Mechanics, Structural Vibration and Stability, Computational Mechanics, Acoustics and Fluid-Solid Interactions, Computer-Aided Engineering Design and Multidisciplinary Design Optimization.

Niels' professional career included military service in the Danish Navy (1965-67), followed by academic activities at the TU Denmark, where he started as a Ph.D. student but soon reached the position of Associate Professor. Since 1985 he has been a full professor at Aalborg University.

He has received numerous awards and honours, amongst many others the Esso Prize, Max Planck Research Award, and membership of the Danish Academy of Technical Sciences and of the Royal Society of Arts and Sciences in Gothenburg, Sweden. He was recently decorated as Knight of Dannebrog by the Queen of Denmark.

As an extremely active and very popular central figure in our society, ISSMO, he has been a member of the Executive Committee since its founding in 1991, Vice-President (1995-1999), and President since 1999. He also organized, together with the writer, the first World Congress of Structural and Multidisciplinary Op-

Published online: 30 October 2003

(C) Springer-Verlag 2003

\section{G.I.N. Rozvany}

Dept. of Structural Mechanics, Faculty of Civil Engineering, Budapest University of Technology and Economics, Müegyetem rkpt. 3, Kmf 35, H-1521 Budapest, Hungary e-mail: rozvany@eik.bme.hu

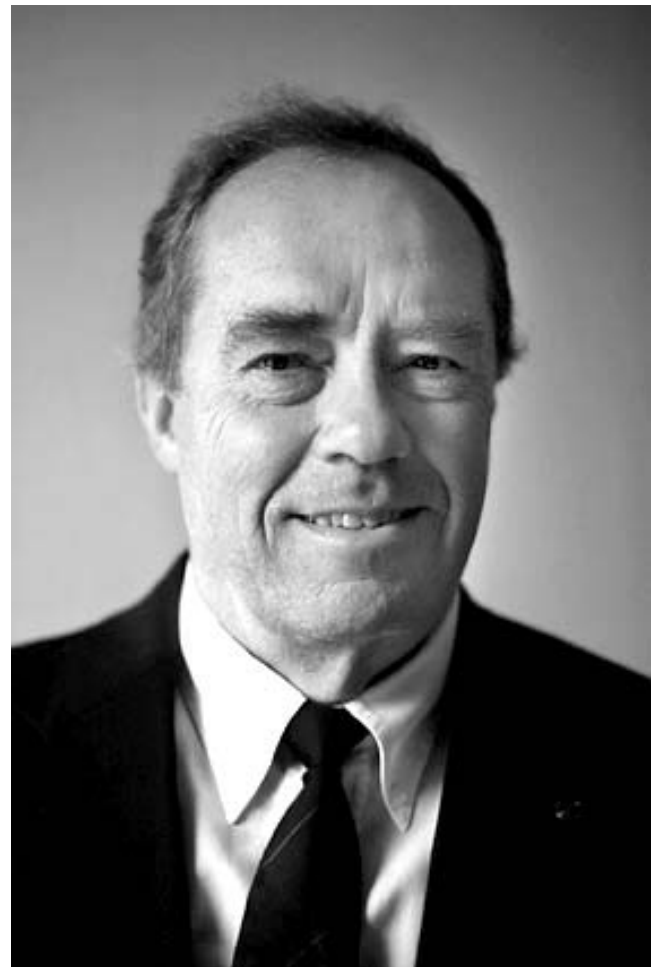

Fig. 1 A recent photo of Niels Olhoff

timization (WCSMO-1) in Goslar, Germany, in 1995. The Editors of this journal are deeply indebted to Niels for his pivotal support, ranging from an often cited paper in the very first issue, followed by a number of milestone contributions later, and his highly creative ideas as a member of the Editorial Board and later as Senior Advisor. He has also been helping with the editing of four other journals and has acted as referee for 26 scientific periodicals.

Niels has also played a key role in several other societies and professional institutions, particularly the IUTAM, in which he has been Secretary of the Congress Committee (1992-2000) and Danish delegate to the General Assembly (since 1991).

He has carried out joint research on an international scale with many scientists from other countries, including Russia, the U.S.A., as well as Western and Central Europe. 
Niels has always been a very keen football (soccer) player. In the sixties he played for the famous Danish club AB (Akademisk Boldklub - still in existence, see www.abfodbold.dk) as a defender and captain of their team in the Premier League in Denmark. He continued to play for many years for $\mathrm{AB}$, even after moving to Aalborg. He is now active in the Aalborg club Chang, where he plays old-boys football. He also likes to play with colleagues at the Department and when attending conferences (the matches between Scandinavia and the rest of the world are legends in our field).

The writer has known Niels since the IUTAM congress in Moscow in 1972, after which he enjoyed Niels' supreme hospitality in Denmark on several occasions. This association intensified during the NATO ASI in Iowa City in 1980, resulting in many research communications and 6 joint research papers. Niels also visited the writer at his institute in Essen University, Germany, on several occasions, where he also acted as the examiner of the writer's doctoral students. This was followed by the joint organization of two international meetings (WCSMO-1 and the NATO ARW in Budapest in 2000), including joint editing of the conference proceedings (hard cover, 991 and 411 pages, respectively).

Niels' outstanding talents were already pointed out to the writer by William Prager, shortly before the tragic death of the latter in 1980: he regarded Niels as the most talented young researcher in the field, and his revolutionary discoveries (optimal solutions for multiple eigenvalues and grid-like formations in the optimal design of continua) as some of the most important in structural optimization in the 20th century.

I am sure that the entire optimization community will join the writer in wishing Niels a long and fruitful continuation of his brilliant carreer.

1

\section{Publications, Niels Olhoff}

1.1

Theses

Olhoff, N. 1969: Optimal design of circular plates (in Danish). Thesis for the Degree of Lic. Techn. (Ph.D.), Dept. of Solid Mechanics, The Technical University of Denmark

Olhoff, N. 1978: Optimal design against structural vibration and instability. Thesis for the Degree of Dr. Techn., Dept. of Solid Mechanics, The Technical University of Denmark

\section{2 \\ Monograph}

Olhoff, N. 1981: Optimal structural design (in Russian). Lurie, K.A.; Cherkaev, A.V. (eds.), pp. 276 Moscow: MIR Publishers
1.3

Teaching material and textbooks

Olhoff, N. (ed.) 1970: Collection of problems in strength of materials, Vol. 1 (in Danish). Lyngby: Polyteknisk Forlag; 2nd edn. 1974

Olhoff, N. (ed.) 1970: Collection of problems in strength of materials, Vol. 2 (in Danish). Lyngby: Polyteknisk Forlag; 2nd edn. 1974

Olhoff, N. 1979: Introduction to fracture mechanics (in Danish). In: Materialenyt (Danish Society for Materials Testing and Research), No. 2, pp. 3-45

Olhoff, N. 1982: Lecture notes for strength of materials II (in Danish). Lyngby: Dept. of Solid Mechanics, Technical University of Denmark; 2nd edn. 1992

Olhoff, N. (ed.) 1982: Collection of problems for strength of materials II (in Danish). Lyngby: Dept. of Solid Mechanics, Technical University of Denmark

Eschenauer, H.; Olhoff, N.; Schnell, W. 1996: Applied structural mechanics: fundamentals of elasticity, loadBearing structures, and structural optimization, including exercises. Berlin: Springer-Verlag

Olhoff, N.; Gudmann Nielsen, A. 2001: Lecture notes for strength of materials, 3rd edn. (in Danish). Lyngby: Dept. of Solid Mechanics, Technical University of Denmark

\section{4 \\ Popular science}

Olhoff, N. 1998: Design of optimum structures (in Danish). In: Naturens Verden, pp. 346-354. Copenhagen: Forlaget Rhodos

\section{5 \\ Editorship of proceedings}

Eschenauer, H.; Olhoff, N. (eds.) 1983: Optimization methods in structural design (Euromech-Colloquium 164 held in Siegen 1982). Zürich: Bibliographisches Institut,

Niordson, F.; Olhoff, N. (eds.) 1985: Theoretical and applied mechanics (XVIth Int. Congr. Theoretical and Applied Mechanics held in Lyngby 1984). Amsterdam: North-Holland Publishing Company

Olhoff, N.; Kibsgaard, S. (eds.) 1989: Computer aided optimal structural design, Vols. 1 and 2 (Lecture notes for course within European Programme for Advanced Education (COMETT) held in Aalborg). Aalborg: Institute of Mechanical Engineering, Aalborg University

Eschenauer, H.; Mattheck, C.; Olhoff, N. (eds.) 1991: Engineering optimization in design processes (Int. Conf., Karlsruhe Nuclear Research Center, held in Karlsruhe 1990). Berlin: Springer-Verlag

Olhoff, N.; Rasmussen, J. (eds.) 1993: Computer aided optimum design of structures, Vols. 1 and 2 (Lecture notes for COMETT Course held in Aalborg). Aalborg: Institute of Mechanical Engineering, Aalborg University

Olhoff, N. (ed.) 1994: Concurrent engineering tools for dynamic analysis and optimization, Vols. 1 and 2 (lecture 
notes) (5th IUTAM International Summer School on Mechanics held in Aalborg)

Olhoff, N.; Rozvany, G.I.N. (eds.) 1995: Structural and multidisciplinary optimization (1st World Congr. Structural and Multidisciplinary Optimization held in Goslar). Oxford: Pergamon Press

Rozvany, G.I.N.; Olhoff, N. (eds.) 2000: Topology optimization of structures and composite continua (NATO Advanced Research Workshop held in Budapest). Dordrecht: Kluwer Academic Publishers

Bendsoe, M.P.; Olhoff, N.; Rasmussen, J. (eds.) 2001: Proc. 2nd Max Planck Workshop on Engineering Design Optimization (held in Nyborg). Lyngby: Technical University of Denmark and Institute of Mechanical Engineering, Aalborg University

Lund, E.; Olhoff, N.; Stegmann, J. (eds.) 2002: Proc. 15th Nordic Seminar on Computational Mechanics, NSCM 15 (held in Aalborg). Aalborg: Institute of Mechanical Engineering, Aalborg University

Pedersen, P.; Olhoff, N. (eds.) 2003: Proc. DCAMM International Symposium on Challenges in Applied Mechanics (the Frithiof Niordson Volume) (held in Lyngby, Denmark). Lyngby: The Danish Center for Applied Mathematics and Mechanics (DCAMM), Technical University of Denmark and Aalborg University

\section{6}

\section{Articles in refereed international journals}

Olhoff, N. 1970: Optimal design of vibrating circular plates. Int. J. Solids Struct. 6, 139-156

Olhoff, N. 1974: Optimal design of vibrating rectangular plates. Int. J. Solids Struct. 10, 93-109

Olhoff, N. 1976: Optimization of vibrating beams with respect to higher order natural frequencies. J. Struct. Mech. 4, 87-122

Olhoff, N. 1976: A survey of the optimal design of vibrating Structural Elements, Part I: Theory. Shock Vib. Dig., 8, 3-10

Olhoff, N. 1976: A survey of the optimal design of vibrating structural elements, part II: applications. Shock Vib. Dig. 8, 3-10

Olhoff, N. 1977: Maximizing higher order eigenfrequencies of beams with constraints on the design geometry. J. Struct. Mech. 5, 107-134

Olhoff, N.; Rasmussen, S.H. 1977: On single and bimodal optimum buckling loads of clamped columns. Int. J. Solids Struct. 12, 605-614

Olhoff, N.; Taylor, J.E. 1978: Designing continuous columns for minimum total cost of material and interior supports. J. Struct. Mech. 6, 367-382

Olhoff, N.; Taylor, J.E. 1979: On optimal structural remodeling. J. Optim. Theory Appl. 27, 571-582

Olhoff, N.; Niordson, F. 1979: Some problems concerning singularities of optimal beams and columns. ZAMM 59, T16-T26
Cheng, K.-T.; Olhoff, N. 1981: An investigation concerning optimal design of plates. Int. J. Solids Struct. 17, 305-323

Olhoff, N.; Lurie, K.A.; Cherkaev, A.V.; Fedorov, A.V. 1981: Sliding regimes and anisotropy in optimal design of vibrating axisymmetric plates. Int. J. Solids Struct. 17, 931-948

Lekszycki, T.; Olhoff, N. 1981: Optimal design of viscoelastic structures under forced steady state vibration. J. Struct. Mech. 9, 363-387

Cheng, K.-T.; Olhoff, N. 1982: Regularized formulation for optimal design of axisymmetric plates. Int. J. Solids Struct. 18, 153-169

Rozvany, G.I.N.; Olhoff, N.; Cheng, K.-T.; Taylor, J.E. 1982: On the solid plate paradox in structural optimization. J. Struct. Mech. 10, 1-32

Olhoff, N.; Rozvany, G.I.N. 1982: Optimal grillage layout for given natural frequency. J. Eng. Mech. ASCE 108, EM5, 971-975

Plaut, R.H.; Olhoff, N. 1983: Optimal forms of shallow arches with respect to vibration and stability. J. Struct. Mech. 11, 81-100

Olhoff, N.; Plaut, R.H. 1983: Bimodal optimization of vibrating shallow arches. Int. J. Solids Struct., 19, $553-570$

Olhoff, N.; Parbery, R. 1984: Designing vibrating beams and rotating shafts for maximum difference between adjacent natural frequencies. Int. J. Solids Struct. 20, 63-75

Wang, C.-M.; Rozvany, G.I.N.; Olhoff, N. 1984: Optimal plastic design of axisymmetric solid plates with a minimum thickness constraint. Comput. Struct., 18, 653-665

Bendsøe, M.P.; Olhoff, N.; Taylor, J.E. 1983: A variational formulation for multicriteria structural optimization. J. Struct. Mech. 11, 523-544

Olhoff, N.; Taylor, J.E. 1983: On structural optimization. 50th Anniversary issue of J. Appl. Mech. Trans. ASME, 1139-1151

Plaut, R.H.; Johnson, L.W.; Olhoff, N. 1986: Bimodal optimization of compressed columns on elastic foundations. J. Appl. Mech., Trans. ASME 53, 130-134

Bendsøe, M.P.; Olhoff, N.; Sokolowski, J. 1985: Sensitivity analysis of problems of elasticity with unilateral constraints. J. Struct. Mech. 13, 201-222

Wang, C.-M.; Thevendran, V.; Rozvany, G.I.N.; Olhoff, N. 1986: Optimal plastic design of circular plates: numerical solutions and build-in edges. Comput. Struct. 22, 519-528

Bendsøe, M.P.; Olhoff, N. 1985: A method of design against vibration resonance of beams and shafts. Opt. Control Appl. Methods 6, 191-200

Bendsøe, M.P.; Olhoff, N.; Taylor, J.E. 1987-88: On the design of structure and controls for optimal performance of actively controlled flexible structures. Mech. Struct. Mach. 15, 265-295

Parbery, R.; Olhoff, N. 1987-88: Optimal design of thin-walled cylinders of variable wall-thickness subject to 
flexural and torsional stiffness constraints. Mech. Struct. Mach. 15, 347-357

Rozvany, G.I.N; Ong, T.G.; Szeto, W.T.; Sandler, R.; Olhoff, N.; Bendsøe, M.P. 1987: Least-weight design of perforated elastic plates-I. Int. J. Solids Struct. 23, $521-536$

Rozvany, G.I.N; Ong, T.G.; Szeto, W.T.; Sandler, R.; Olhoff, N.; Bendsøe, M.P. 1987: Least-weight design of perforated elastic plates - II. Int. J. Solids Struct. 23, 537-550

Åkesson, B.; Olhoff, N. 1988: Minimum stiffness of optimally located supports for maximum value of beam eigenfrequencies. J. Sound Vib. 120, 457-463

Olhoff, N. 1989: Multicriterion structural optimization via bound formulation and mathematical programming. Struct. Optim. 1, 11-17

Thomsen, J.; Olhoff, N. 1990: Optimization of fiber orientation and concentration in composites. Control $C y$ bern. 19, No. 3-4

Olhoff, N.; Åkesson, B. 1991: Minimum stiffness of optimally located supports for maximum value of column buckling loads. Struct. Optim. 3, 163-175

Olhoff, N.; Bendsøe, M.P.; Rasmussen, J. 1991: On CAD-integrated structural topology and design optimization. Comput. Methods Appl. Mech. Eng. 89, 259-279

Olhoff, N.; Rasmussen, J. 1991: Study of inaccuracy in semi-analytical sensitivity analysis - a model problem. Struct. Optim. 3, 203-213

Lekszycki, T.; Olhoff, N.; Pedersen, J.J. 1992: Modelling and identification of viscoelastic properties of vibrating sandwich beams. Compos. Struct. 22, 15-31

Cheng, G.D.; Olhoff, N. 1993: Rigid body motion test against error in semi-analytical sensitivity analysis. Comput. Struct. 46, 515-527

Olhoff, N.; Lund, E.; Rasmussen, J. 1993: Method of "exact" numerical differentiation for error elimination in finite element based semi-analytical shape sensitivity analyses. Mech. Struct. Mach. 21, pp. 1-66

Rasmussen, J.; Lund, E.; Birker, T.; Olhoff, N. 1993: The CAOS system. Int. Ser. Numer. Math. 110, 75-96

Lund, E.; Olhoff, N. 1994: Shape design sensitivity analysis of eigenvalues using "exact" numerical differentiation of finite element matrices. Struct. Optim. 8, 52-59

Seyranian, A.P.; Lund, E.; Olhoff, N. 1994: Multiple eigenvalues in structural optimization problems. Struct. Optim. 8, 207-227

Olhoff, N. 1996: On optimum design of structures and materials. Meccanica 31, 143-161

Jacobsen, J.B.; Olhoff, N.; Rønholt, E. 1998: Generalized shape optimization of three-dimensional structures using materials with optimum microstructures. Mech. Mater. 28, 207-225

Christensen, S.T.; Olhoff, N. 1998: Shape optimization of a loudspeaker diaphragm with respect to sound directivity properties. Control Cybern. 27, 177-198

Christensen, S.T.; Sorokin, S.V.; Olhoff, N. 1998: On analysis and optimization in structural acoustics - part I: problem formulation and solution techniques. Struct. Optim. 16, 83-95
Christensen, S.T.; Sorokin, S.V.; Olhoff, N. 1998: On analysis and optimization in structural acoustics - part II: exemplification for axisymmetric structures. Struct. Optim. 16, 96-107

Olhoff, N.; Rønholt, E.; Scheel, J. 1998: Topology optimization of three-dimensional structures using optimum microstructures. Struct. Optim. 16, 1-18

Foldager, J.; Hansen, J.S.; Olhoff, N. 1998: A general approach forcing convexity of ply angle optimization in composite laminates. Struct. Optim. 16, 201-211

Chou, F.S.; Wang, C.M.; Cheng, G.D.; Olhoff, N. 1999: Optimal design of internal ring supports for vibrating circular plates. J. Sound Vib. 219, 525-537

Krog, L.A.; Olhoff, N. 1999: Optimum topology and reinforcement design of disk and plate structures with multiple stiffness and eigenfrequency objectives. Comput. Struct., 72, 535-563

Hammer, V.B.; Olhoff, N. 2000: Topology optimization of continuum structures subjected to pressure loading. Struct. Multidisc. Optim. 19, 85-92

Foldager, J.; Hansen, J.S.; Olhoff, N. 2001: Optimization of the buckling load for composite structures taking thermal effects into account. Struct. Multidisc. Optim. 21, $14-31$

Hansen, J.S.; Liu, Z.S.; Olhoff, N. 2001: Shape sensitivity analysis using a fixed basis function finite element approach. Struct. Multidisc. Optim. 21, 177-195

Sorokin, S.V.; Nielsen, J.B.; Olhoff, N. 2001: Analysis and optimization of energy flows in structures composed of beam elements - part I: problem formulation and solution technique (Co-authors S.V. Sorokin, J.B. Nielsen). Struct. Multidisc. Optim. 22, 3-11

Sorokin, S.V.; Nielsen, J.B.; Olhoff, N. 2001: Analysis and optimization of energy flows in structures composed of beam elements - part II: examples and discussion. Struct. Multidisc. Optim. 22, 12-23

Eschenauer, H.A.; Olhoff, N. 2001: Topology optimization of continuum structures - a review. Appl. Mech. Rev. 54, 331-390

Langthjem, M.; Olhoff, N. 2003: Modal expansion of the perturbation velocity potential for a cantilevered fluidconveying cylindrical shell. J. Fluids Struct. 17, 147-161

Sorokin, S.V.; Nielsen J.B.; Olhoff, N. 2002: Energy flows in cylindrical shells with and without internal fluid loading. J. Sound Vib. (accepted)

Langthjem, M.; Olhoff, N. 2002: A numerical study of flow-induced noise in a centrifugal pump. part I, hydrodynamics. J. Fluids Struct. (accepted)

Langthjem, M.; Olhoff, N. 2002: A numerical study of flow-induced noise in a centrifugal pump. part II, hydroacoustics. J. Fluids Struct. (accepted)

Kharmanda, G.; Olhoff, N.; Mohamed, A.; Lemaire, M. 2003: Reliability-based topology optimization. Struct. Multidisc. Optim. (accepted)

Du, J.; Olhoff, N. 2003: Topological optimization of continuum structures with design-dependent surface loading - part I: new computational approach for $2 \mathrm{D}$ problems. Struct. Multidisc. Optim. (accepted) 
Du, J.; Olhoff, N. 2003: Topological optimization of continuum structures with design-dependent surface loading - part II: algorithm and examples for 3D problems. Struct. Multidisc. Optim. (accepted)

Kharmanda, G.; Olhoff, N.; El-Hami, A. 2003: Optimum values of structural safety factors for a predefined reliability level with extension to multiple limit states. Struct. Multidisc. Optim. (accepted)

Guo, X.; Cheng, G.D.; Olhoff, N. 2003: Optimum design of truss topology under buckling constraints. Struct. Multidisc. Optim. (submitted)

\section{7 \\ Papers in proceedings and monographs}

Olhoff, N. 1975: On singularities, local optima and formation of stiffeners in optimal design of plates. In: Sawczuk, A.; Z. Mróz (eds.) Proc. IUTAM Symp. Optimization in Structural Design (held in Warsaw 1973), pp. 82-103. Berlin: Springer-Verlag

Olhoff, N. 1977: On optimal design of vibrating structures (in Polish). In: Mróz, Z. (ed.) Proc. Metody Optymalizacji W Teorii Konstrukcji (held in Warsaw 1975), pp. 53-72. Warsaw: Ossolineum

Olhoff, N. 1977: Optimization of vibrating beams with respect to higher order natural frequencies (in Polish). In: Mróz, Z. (ed.) Proc. Metody Optymalizacji W Teorii Konstrukcji, (held in Warsaw 1975), pp. 73-115. Warsaw: Ossolineum

Olhoff, N.; Niordson, F. 1979: Variational methods in optimization of structures. In: Besseling, J.F.; van der Heijden, A.M.A. (eds.) Proc. Symp. "Trends in Solid Mechanics", pp. 177-194. Delft Univ. Press, Delft: Sijthoff and Noordhoff

Olhoff, N. 1980: Fracture mechanics under static loading and fatigue (in Danish). In: Langer, E.W.; Nielsen, T.S. (eds.) Cracks and fracture, pp. 41-58. Copenhagen: Danish Metallurgical Society

Olhoff, N. 1980: Chairman's summary on session J, optimization and plasticity. In: Nemat-Nasser, S. (ed.) Proc. IUTAM Symp. Variational Methods in the Mechanics of Solids (held in Evanston 1978), p. 335. Oxford: Pergamon Press

Olhoff, N. 1980: Optimal design with respect to structural eigenvalues. In: Rimrott, F.P.J.; Tabarrok, B. (eds.) Proc. XVth Int. IUTAM Congr. Theoretical and Applied Mech. (held in Toronto), pp. 133-149. Amsterdam: North-Holland

Olhoff, N. 1981: Optimization of transversely vibrating beams and rotation shafts. In: Haug, E.J.; Cea, J. (eds.) Proc. Advanced Study Institute "Optimization of Distributed Parameter Structures", Vol. 1 (held in Iowa City 1980), pp. 177-199. Alphen aan den Rijn: Sijthoff and Noordhoff

Olhoff, N. 1981: Optimization of columns against buckling. In: Haug, E.J.; Cea J. (eds.) Optimization of distributed parameter structures, Vol. 1 (Proc. Advanced
Study Institute held in Iowa City 1980), pp. 152-176. Alphen aan den Rijn: Sijthoff and Noordhoff

Olhoff, N. 1981: Optimal design of solid elastic plates (Co-author K.-T. Cheng). In: Haug, E.J.; Cea J. (eds.) Optimization of distributed parameter structures, Vol. 1 (Proc. Advanced Study Institute held in Iowa City 1980), pp. 278-303. Alphen aan den Rijn: Sijthoff and Noordhoff

Olhoff, N. 1982: Structural optimization by variational methods. In: Brouse, P. (ed.) Optimization of structures, mathematical foundations and applications (International Centre for Mechanical Sciences, Udine, Italy), $97 \mathrm{pp}$.

Olhoff, N. 1983: Fracture mechanics research in Denmark. In: Sih, G.C.; Francois, D. (eds.) Progress in fracture mechanics, pp. 29-33. Oxford: Pergamon Press

Olhoff, N. 1983: Bimodality in optimizing the shape of a vibrating shallow arch. In: Eschenauer, H.; Olhoff, N. (eds.) Optimization methods in structural design (Euromech-Colloquium 164 held in Siegen 1982), pp. 97102. Zürich: Bibliographisches Institut

Bendsøe, M.P.; Olhoff, N. 1983: Control of the natural frequencies of vibrating beams and rotating shafts. In: Applied control and identification, Vol. 1 (1st IASTED Symp. held in Copenhagen), pp. 1/18-1/23. Copenhagen, Lyngby: Control Engineering Institute, The Technical University of Denmark

Olhoff, N.; Parbery, R. 1984: Optimal structural design for maximum distance between adjacent eigenfrequencies. In: Thoft-Christensen, P. (ed.) In: System modelling and optimization (11th IFIP Conference held in Copenhagen 1983), pp. 765-772. Berlin: Springer-Verlag

Olhoff, N. 1986: Structural optimization by variational methods. In: Mota Soares, C.A. (ed.) Computer aided optimal design: structural and mechanical systems (NATO ASI held in Troia 1986), pp. 87-164. Berlin, Heidelberg, New York: Springer-Verlag

Olhoff, N. 1988: Variational methods in structural eigenvalue optimization. In: Chenais, D.; Rousselet, B. (ed.) Conception optimale de structures assistee par ordinateur (Textes des Communications de L'Ecole d'Ete held in Sophia-Antipolis), 56 pp. Nice: Departement de Mathematiques, Universite de Nice

Olhoff, N. 1989: Optimal structural design via bound formulation and mathematical programming. In: Eschenauer, H.; Thierauf, G. (eds.) Discretization methods and structural Optimization, procedures and applications (GAMM-Seminar held in Siegen 1988), pp. 255-262. Berlin: Springer-Verlag

Kibsgaard, S.; Olhoff, N.; Rasmussen, J. 1989: Concept of an optimization system. In: Brebbia, C.A.; Hernandez, S. (eds.) Computer aided optimum design of structures: applications (1st. Int. Conf. held in Southampton), pp. 79-88. Berlin: Springer-Verlag

Olhoff, N. 1989: Optimal design of conservative mechanical systems. In: Zyczkowski, M. (ed.) Structural optimization under stability and vibration constraints, Part III (CISM Lecture Notes), pp. 145-212. Berlin: SpringerVerlag 
Han, Z.; Lauritsen, S.; Olhoff, N. 1990: An application of knowledge engineering technology in design of cam mechanisms. In: Hubka, V.; Kostelic, A. (eds.) Proc. Int. Conf. Eng. Design (ICED), Vol. 4 (held in Dubrovnik), pp. 1740-47. Belgrade: Yugoslav Society of Machine Elements and Design

Bendsøe, M.P.; Olhoff, N.; Taylor, J.E. 1990: A unified approach to the analysis and design of elasto-plastic structures with mechanical contact. In: Recent Advances in Multidisciplinary Analysis and Optimization (3rd Air Force/NASA Symp. held in San Francisco)

Olhoff, N.; Bendsøe, M.P.; Rasmussen, J. 1992: On CAD-integrated structural topology and design optimization. In: Rozvany, G.I.N. (ed.) Shape and layout optimization of structural systems and optimality criteria methods. Courses and lectures - No. 325 (Int. Centre Mechanical Sciences, Udine, Italy), pp. 171-197. Wien: Springer-Verlag

Olhoff, N.; Rasmussen, J. 1991: Method of error elimination for a class of semi-analytical sensitivity analysis problems. In: Eschenauer, H.A.; Mattheck, C.; Olhoff, N. (eds.) Proc. Int. Conf. Engineering Optimization in Design Processes (Lecture notes in engineering 63) (held in Karlsruhe 1990), pp. 193-200. Berlin: Springer-Verlag

Rasmussen, J.; Thomsen, J.; Olhoff, N. 1992: Integrating topology and boundary variations design methods in a CAD system. In: Bendsøe, M.P.; Mota Soares, C.A. (eds.) Topology design of structures, pp. 483-500. Dordrecht: Kluwer

Olhoff, N.; Rovati, M. 1992: Structural optimal design with respect to stability and vibrations. In: SacchiLandriani, G.; Salencon, J. (eds.) On the evaluation of global bearing capacities of structures (lecture notes) (Int. Centre Mechanical Sciences, Udine, Italy)

Olhoff, N.; Lund, E.; Rasmussen, J. 1992: Foundations for optimumdesignsystem development.In:Burczynski, T. (ed.) Lecturenotes, Advanced TEMPUS course on computer aidedoptimaldesign, Vol.1 (heldinZakopane),pp.168-240. Poland: Silesian Technical University of Gliwice

Bendsøe, M.P.; Olhoff, N.; Taylor, J.E. 1993: A unified approach to the analysis and design of elasto-plastic structures with mechanical contact. In: Rozvany, G.I.N. (ed.) Optimization of large structural systems, Vol. 2, pp. 697-705. Dordrect: Kluwer Academic Publishers

Cheng, G.; Olhoff, N. 1993: A new method of error analysis and detection in semi-analytical sensitivity analysis. In: Rozvany, G.I.N (ed.) Optimization of large structural systems, Vol. 1, pp. 361-383. Dordrecht: Kluwer Academic Publishers

Lund, E.; Olhoff, N. 1993: Reliable and efficient finite element based design sensitivity analysis of eigenvalues. In: Proc. Structural Optimization 93 (World Congr. Optimal Design of Structural Systems held in Rio de Janeiro)

Olhoff, N.; Rasmussen, J. 1993: Method of error elimination for a class of semi-analytical sensitivity analysis problems. In: Rozvany, G.I.N. (ed.) Optimization of large structural systems, Vol. 1, pp. 385-396. Dordrecht: Kluwer Academic Publishers
Olhoff, N.; Lund, E.; Rasmussen, J. 1993: Concurrent engineering design optimization in a CAD environment. In: Haug, E.J. (ed.) Concurrent engineering tools and technologies for mechanical system design (NATOARMY-NASA Advanced Study Institute held in Iowa 1992), pp. 523-586. New York: Springer-Verlag

Olhoff, N.; Thomsen, J.; Rasmussen, J. 1993: Topology optimization of bi-material structures. In: Pedersen, P. (ed.) Optimal design with advanced materials (IUTAM Symposium held in Lyngby 1992), pp. 191-206. Berlin: Springer-Verlag

Lund, E.; Rasmussen, J.; Olhoff, N.; Birker, T. 1993: Structural topology and shape optimization with the CAOS system. In: Lecture notes for COMETT course on computer aided optimal design (held in Eindhoven)

Rasmussen, J.; Lund, E.; Olhoff, N. 1993: Parametric modeling and analysis for optimum design. In: Proc. Structural Optimization 93 (World Congr. Optimal Design of Structural Systems held in Rio de Janeiro)

Olhoff, N.; Krog, L.; Thomsen, J. 1993: Bi-material topology optimization. In: Proc. Structural Optimization 93 (World Congr. Optimal Design of Structural Systems held in Rio de Janeiro)

Rasmussen, J.; Lund, E.; Olhoff, N. 1993: Integration of parametric modeling and structural analysis for optimum design. Proc.: Gilmore et al. : Advances in Design Automation. Albuquerque: The American Society of Mechanical Engineers

Olhoff, N.; Thomsen, J. 1993: Optimization of fiber orientation and concentration in composites. In: Sacchi Landriani, G.; Salencon, J. (eds.) Evaluation of global bearing capacities of structures (International Centre for Mechanical Sciences, Udine, Italy), pp. 221-235. Vienna: Springer-Verlag

Olhoff, N.; Lund, E.; Seyranian, A.P. 1994: Sensitivity analysis and optimization of multiple eigenvalues in structural design problems. In: American Institute of Aeronautics and Astronautics: A collection of technical papers, Vol. 1 (5th AIAA/NASA/USAF/ISSMO Symp. Multidisciplinary Analysis and Optimization held in Panama City), pp. 625-640

Lund, E.; Olhoff, N. 1995: Finite element based engineering design sensitivity analysis and optimization. In: Herskovits, J. (ed.) Advances in structural optimization, pp. 1-45. Dordrecht: Kluwer Academic Publishers

Krog, L.A.; Olhoff, N. 1995: Topology optimization of plate and shell structures with multiple eigenfrequencies. In: Olhoff, N.; Rozvany, G.I.N. (eds.) Proc. 1st World Congress of Structural and Multidisciplinary Optimization (held in Goslar), pp. 675-682. Oxford: Pergamon Press

Olhoff, N.; Krog, L.A.; Lund, E. 1995: Optimization of multimodal structural eigenvalues. In: Olhoff, N.; Rozvany, G.I.N. (eds.) Proc. 1st World Congress of Structural and Multidisciplinary Optimization (held in Goslar), pp. 701-708. Oxford: Pergamon Press

Krog, L.A.; Olhoff, N. 1996: Topology optimization of integral rib reinforcement of plate and shells structures 
with weighted-sum and max-min objectives. In: Bestle, D.; Schiehlen, W. (eds.) Proc. IUTAM Symp. Optimization of Mechanical Systems (held in Stuttgart 1995), pp. 171-180. Dordrecht: Kluwer Academic Publishers

Olhoff, N. 1995: On optimum design of structures and materials. In: Augusti, G.; Nunziante, L. (ed.) Proc. XIIth Natl. Congr. Italian Assoc. Theoretical and Appl. Mech., Vol. 1 - General lectures (held in Naples) Rome: AIMETA

Lund, E.; Olhoff, N. 1996: Design sensitivity analysis and optimization based on "exact" semi-analytical method . In: Zhong, W.; Cheng, G.; Li, X. (eds.) The advances in computational mechanics, pp. 183-208. Beijing: Int. Academic Publishers

Olhoff, N.; Bogdan, L. 1995: On inaccuracy in semianalytical sensitivity analysis for Timoshenko beams. In: Malanowski, K.; Nahorski, Z.; Peszynska, M. (eds.) Modelling and optimization of distributed parameter systems applications to engineering, pp. 354-361. London: Chapman and Hall

Christensen, S.T.; Olhoff, N. 1996: Optimization of the directivity of a loadspeaker diaphragm. In: Damkilde, L. (ed.) Proc. 9th Nordic Seminar on Computational Mechanics (held in Lyngby), pp. 107-110. Lyngby: Department of Structural Engineering and Materials, DTU

Olhoff, N. 1996: On engineering design optimization. In: Damkilde, L. (ed.) Proc. 9th Nordic Seminar on Computational Mechanics (held in Lyngby), pp. 1-8. Lyngby: Department of Structural Engineering and Materials, DTU

Kristensen, A.S.; Lund, E.; Rasmussen, J.; Olhoff, N. 1996: Shape design sensitivity analysis and optimization in solid modelling based CAD systems. In: Cinquini, C. (ed.) Intensive school on optimal design, theory, and applications (held in Pavia). Pavia: University of Pavia

Krog, L.A.; Olhoff, N. 1997: Topology and reinforcement layout optimization of disk, plate, and shell structures. In: Rozvany, G. (ed.) Topology optimization in structural mechanics, pp. 237-322. Vienna: SpringerVerlag

Olhoff, N.; Rønholt, E.; Scheel, J. 1997: Three-dimensional structural topology optimization based on optimum microstructures. In: Proc. 2nd World Congr. Structural and Multidisciplinary Optimization (held in Zakopane), pp. 557-562. Warsaw: Institute of Fundamental Technological Research

Krog, L.A.; Olhoff, N.; Rotunno, T. 1997: Topology optimization of non-linearly elastic continuum structures. In: Proc. 13th Italian Congress on Theoretical and Applied Mechanics AIMETA (held in Siena)

Olhoff, N.; Rønholt, E.; Scheel, J. 1997: Optimum 3-D structural topology design based on optimum microstructures. In: Metsaveer, J. (ed.) Proc. 10th Nordic Seminar on Computational Mechanics (held in Tallinn), pp. 188191. Tallinn: Tallinn Technical University

Olhoff, N.; Lund, E. 1997: Finite element based engineering design sensitivity analysis and optimization. In: Wiberg, N.-E.; Wendt, U. (eds.) Proc. FEM-97, Simulation and Optimization (held in Gothenburg)
Chou, F.S.; Wang. C.M.; Cheng, G.; Olhoff, N. 1998: Optimal locations of internal ring supports for vibrating circular plates. In: Caccetta, L.; Teo, K.L.; Siew, P.F.; Leung, Y.H.; Jennings, L.S.; Rehbock, V. (eds.) Proc. Int. Conf. on Optimization Techniques and Applications, Vol. 1 (ICOTA 98 held in Perth), pp. $137-143$

Chen, J.; Olhoff, N. 1998: Universal multi-layer neural network for the creation of response surfaces. In: Proc. Mechanics in Design '98 (held in Nottingham)

Olhoff, N.; Rønholt, E.; Scheel, J. 1998: Topology optimization of plate-like structures using 3-D elasticity and optimum 3-D microstructures. In: American Institute of Aeronautics and Astronautics: A collection of technical papers (7th AIAA/USAF/NASA/ISSMO Symp. Multidisciplinary Analysis and Optimization held in St. Louis), pp. $1853-1863$

Foldager, J.; Olhoff, N.; Hansen J.S. 1998: A novel procedure forcing convexity of ply angle optimization in composite laminates. In: American Institute of Aeronautics and Astronautics: A collection of technical papers (7th AIAA/USAF/NASA/ISSMO Symp. Multidisciplinary Analysis and Optimization held in St. Louis), pp. $880-889$

Olhoff, N.; Eschenauer, H. 1999: On optimum topology design in mechanics. In: Proc. European Conference on Computational Mechanics - ECCM 99 (held in Munich 1999). Munich: Technical University of Munich

Hammer, V.B.; Olhoff, N. 1999: Structural topology optimization with design dependent loads. In: Kouhia, R.; Mikkola, M. (eds.) Proc. 12th Nordic Seminar on Computational Mechanics (held in Helsinki), pp. 65-68. Helsinki: Laboratory of Theoretical and Applied Mechanics, Helsinki University of Technology

M.A. Langthjem; Olhoff, N. 1999: Flow noise in a centrifugal pump. In: Kouhia, R.; Mikkola, M. (eds.) Proc. 12th Nordic Seminar on Computational Mechanics (held in Helsinki), pp. 112-115. Helsinki: Laboratory of Theoretical and Applied Mechanics, Helsinki University of Technology

Madsen, J.I.; Olhoff, N.; Condra, T.J. 2000: Optimization of straight, two-dimensional diffusers by wall contouring and guide vane insertion. In: Bloebaum, C. (ed.) Proc. 3rd World Congr. Structural and Multidisciplinary Optimization (held in Buffalo 1999). Buffalo: State University of New York at Buffalo

Hammer, V.B.; Olhoff, N. 2000: Topology optimization with design dependent loads. In: Bloebaum, C. (ed.) Proc. 3rd World Congr. Structural and Multidisciplinary Optimization (held in Buffalo 1999). Buffalo: State University of New York at Buffalo

Foldager, J.; Hansen, J.S.; Olhoff, N. 2000: A convex formulation in ply-angle optimization. In: Bloebaum, C. (ed.) Proc. 3rd World Congr. Structural and Multidisciplinary Optimization (held in Buffalo 1999). Buffalo: State University of New York at Buffalo

Olhoff, N. 2000: Comparative study of optimizing the topology of plate like structures via plate theory and 3-D 
theory of elasticity. In: Rozvany, G.I.N.; Olhoff, N. (eds.) Topology optimization of structures and composite continua (NATO Advanced Research Workshop held in Budapest), pp. 37-49. Dordrecht: Kluwer Academic Publishers

Cheng, G.; Guo, X.; Olhoff, N. 2000: New formulation for truss topology optimization problems under buckling constraints. In: Rozvany, G.I.N.; Olhoff, N. (eds.) Topology optimization of structures and composite continua (NATO Advanced Research Workshop held in Budapest), pp. 115-131. Dordrecht: Kluwer Academic Publishers

Hammer, V.B.; Olhoff, N. 2000: Optimum topology design with surface dependent loading. In: Proc. 8th AIAA/USAF/NASA/ISSMO Symp. Multidisciplinary Analysis and Optimization (held in Long Beach), AIAA Paper No. 20004735

Langthjem, M.; Olhoff, N. 2001: Analysis and minimization of flow noise in a centrifugal pump. In: Satofuka, N. (ed.) Computational fluid dynamics 2000 (1st Int. Conf. Computational Fluid Dynamics held in Kyoto 2000), pp. 761-762. Berlin: Springer-Verlag

Langthjem, M.; Olhoff, N. 2001: Optimum design of the volute tongue against flow-induced noise in a centrifugal pump. In: Cheng, G.; Gu, Y.; Liu, S.; Wang, Y. (eds.) Proc. 4th World Congr. Structural and Multidisciplinary Optimization (held in Dalian). Dalian: Liaoning Electronic Press

Fynbo, J.; Rasmussen, J.; Olhoff, N. 2001: A directional topology optimization method. In: Cheng, G.; Gu, Y.; Liu, S.; Wang, Y. (eds.) Proc. 4th World Congr. Structural and Multidisciplinary Optimization (held in Dalian). Dalian: Liaoning Electronic Press

Hammer, V.B.; Olhoff, N. 2001: Topology optimization of 3D structures with design dependent loads. In: Cheng, G.; Gu, Y.; Liu, S.; Wang, Y. (eds.) Proc. 4th World Congr. Structural and Multidisciplinary Optimization (held in Dalian). Dalian: Liaoning Electronic Press

Langthjem, M.; Olhoff, N. 2001: Modal expansion of the perturbation velocity potential for a cantilevered fluid-conveying shell. In: Beldie, L.; Dahlblom, O.; Olsson, A.; Sandberg, G. (eds.) Proc. 13th Nordic Seminar on
Computational Mechanics (held in Lund), pp. 239-242. Lund: Structural Mechanics, University of Lund

Fynbo, J.; Rasmussen, J.; Olhoff, N. 2001: 2D directional topology optimization. In: Proc. Conf. Architectural Research and Information Technology (held in Aarhus 2001), pp. 113-117. Aarhus: Aarhus School of Architecture

Olhoff, N.; Seyranian, A.P. 2002: Initial post-buckling behaviour of bimodal optimal columns. In: Guran, A.; Bremer, H. (eds.) CD-Proc. 1st Int. Congress on Mechatronics (held in Linz 2002). Linz: Johannes Kepler University

Kharmanda, G.; Olhoff, N. 2002: Reliability-based topology optimization as a new strategy to generate different structural topologies. In: Lund, E.; Olhoff, N.; Stegmann, J. (eds.) Proc. 15th Nordic Seminar on Computational Mechanics (held in Aalborg 2002), pp. 211214. Aalborg: Institute of Mechanical Engineering, Aalborg University.

Fynbo, J.; Rasmussen, J.; Olhoff, N. 2002: A cubist topology optimisation method. In: Lund, E.; Olhoff, N.; Stegmann, J. (eds.) Proc. 15th Nordic Seminar on Computational Mechanics (held in Aalborg 2002), pp. 223226. Aalborg: Institute of Mechanical Engineering, Aalborg University.

Olhoff, N.; Seyranian, A.P. 2002: On the bifurcation and initial post-buckling behaviour of bimodal optimal columns. In: Lund, E.; Olhoff, N.; Stegmann, J. (eds.) Proc. 15th Nordic Seminar on Computational Mechanics (held in Aalborg 2002), pp. 249-252. Aalborg: Institute of Mechanical Engineering, Aalborg University, 2002

Sorokin, S.V.; Nielsen, J.B.; Olhoff, N. 2003: Green's matrix and boundary equations for analysis of the energy transmission in cylindrical shells with and without heavy fluid loading. In: Nilsson, A.; Boden, H. (eds.) Proc. 10th International Congress on Sound and Vibration (held in Stockholm 2003), Vol. 8, pp. 4467-4474. Auburn: The International Institute of Acoustics and Vibration (IIAV), Dept. of Mechanical Engineering, Auburn University, AL 36849-5341, USA, 2003 